\title{
INVESTING IN THE EUROPEAN SIZE FACTOR
}

\author{
Juan Laborda $^{\text {a }}$, Ricardo Laborda ${ }^{b, *}$, Jose Olmo $^{c}$ \\ ${ }^{a}$ Instituto de Estudios Bursátiles. Calle Alfonso XI 28014, Madrid, Spain \\ ${ }^{\mathrm{b}}$ Centro Universitario de la Defensa, Academia General Militar. Ctra Huesca s/n 50090, Zaragoza, Spain \\ ${ }^{c}$ Department of Economics, University of Southampton, United Kingdom
}

\begin{abstract}
This paper investigates the role of the size factor for constructing investment portfolios and proposes a dynamic extension that accommodates the riskfree asset and time-varying weights. These weights are determined by a set of state variables given by the term structure of sovereign interest rates, variables describing market risk aversion such as the VIX index and the CRB Industrial return, and indexes reflecting investor sentiment towards the economic outlook. The empirical section explores the suitability of these state variables and analyses the out-of-sample performance of size factors idiosyncratic to the U.S., U.K. and European financial markets that are compared against the dynamic version that optimizes the weights in each period. The results provide support to the different size factors except for periods of economic distress in which the optimal dynamic strategies are clearly superior.
\end{abstract}

Key Words: Performance Evaluation, Size factor, Tactical Asset Allocation, Trading Strategies.

JEL Classification: G11, G19.

*Corresponding author. Tel.: +34 9767076. e-mail address: rlaborda@unizar.es . 


\section{Introduction}

Fama and French $(1993,1996)$ show that the empirical power of the standard Capital Asset Pricing Model for explaining the cross-sectional variation in average equity returns can be highly improved if the portfolios are sorted by size and book-to-market ratios. The components of this three-factor model are specifically defined as the excess return on a market portfolio (Mkt factor), the return on a portfolio that holds long positions in small capitalization stocks (small caps) and short positions in large capitalization stocks (SMB factor), and the return on a portfolio that holds a long position in high book-to-price stocks and a short position in low book-to-price stocks (HML factor).

The financial literature has focused on the search of the economic sources that could elucidate rationally the ability of these factors to explain the cross-sectional variation in average returns of portfolios, giving a risk-based explanation behind the SMB and HML factors. The interest in exploring the profitability of portfolios replicating these factors resides in their ability to capture future changes in the economic environment, such as the impoverishment in credit conditions reflected by an increase of the business failure rates, see Kapadia (2011), changes in the level of economic activity, see Liew and Vassalou (2000), or changes in financial market conditions, such as countercyclical dynamics of the Sharpe ratio, see Quiros and Timmermann (2000). It is, therefore, possible to establish a relationship between the investment strategies replicating the SMB and HML factors and macroeconomic and financial risks.

In this paper we focus on the SMB factor with data from European, U.K. and U.S. financial markets extending existing evidence on the importance of the size factor for U.S. financial markets. Our choice of the SMB factor as opposed to the HML factor 
is due to its higher correlation with variables proxying credit market conditions, monetary policy and business cycle dynamics. The first aim of this paper is to investigate the performance of portfolios that replicate the returns on the SMB factor corresponding to major financial markets and explore different sets of financial variables linked to the stage of the business cycle and market risk premiums capable of predicting the dynamics of such factor. The second goal of the paper is to exploit the predictive power of these variables to envisage dynamic investment strategies providing hedging against downturns of the SMB factor and correlated with credit and macroeconomic conditions. The dynamic hedging strategy is achieved by making allowance for a risk-free asset that completes the investment opportunity set available to the investor. In this simple investment framework the optimal strategy consists of a vector of time-varying weights that allows investors with interests in positioning on the SMB factor to switch between long and short positions in the risk-free asset and the SMB factor depending on extant credit and macroeconomic conditions in each period. In this setting, investors obtain their optimal strategy by maximizing in each period the expected utility on their investment portfolio return. This methodology has been originally exploited in optimal portfolio theory in the seminal articles by Brandt (1999), Ait-Sahalia and Brandt (2001) or Brandt, Santa Clara, and Valkanov (2009).

We empirically assess the relevance of the size factor as an investment strategy and its performance compared to the counterpart dynamic strategy with data from the European, U.K. and U.S. financial markets. Our empirical analysis reveals that the set of financial variables with power to explain the SMB factor is related to the yield curve on sovereign debt, overall credit conditions, market risk aversion and investor economic sentiment. The performance of the different dynamic optimal portfolios is compared against the corresponding country-specific passive SMB portfolios by means of 
statistical and economic measures such as the Sharpe and Sortino ratios and the difference in certainty equivalent returns (CERs) between strategies obtained under the assumption that individual preferences exhibit constant relative risk aversion. The main findings of the empirical section are summarized as follows.

First, for each economy we provide empirical support for the existence of an investment style characterized by a portfolio tracking the returns on the size factor. The return on this portfolio is determined by the differences in performance between small and large firms in terms of asset capitalization. The portfolio corresponding to the size factor investment style performs very well during periods of low and decreasing interest rates and high liquidity, and poorly during periods of monetary tightening and episodes of high uncertainty in financial markets. The first regime reflects a positive correlation between favourable financial conditions, an improvement in the access to credit by small firms and decreasing market risk aversion. The second regime is usually identified with periods of flight to quality and liquidity and a correction of overvalued equities.

Second, large firms outperform small firms during turmoil periods. From an empirical perspective these findings motivate the construction of simple dynamic strategies allowing for short positions in the size factor with the aim of hedging against economic downturns. Thus, our results over a sample covering twenty years of monthly returns clearly show the statistical and economic gains from switching between short and long positions for the size factor of the three major economies under study. These results are confirmed after the subprime crisis, for which the tactical asset allocation problem suggests that following the passive strategy but avoiding episodes of increasing market risk aversion delivers a high reward to the investor.

Third, our analysis of the dynamics of the optimal portfolio reveal that the weight function determining the investor's optimal position on the size factor is 
negatively related to the level factor of the sovereign yield curve corresponding to each economy, the level factor of the sovereign yield curve momentum, the economic sentiment index idiosyncratic to each economy and the three month change in the VIX index. The size factors are also positively related to the three month change of the CRB Industrial return. The importance of these variables in determining the optimal portfolio allocation resides in their ability to predict the SMB factors over our evaluation periods. The empirical relationship between interest rates and the size factors can be rationalized by noting that low and decreasing interest rates can be associated to easier access to private financing by small caps, enhancing, in turn, their relative valuations compared to large cap stocks. A low interest rate environment also favors the relative performance of small caps compared to large caps by reducing the existence of agency costs in credit markets borne by small caps. The negative relationship between investor sentiment and the size factor can be explained, especially in European markets, by observing that periods of tightening in monetary policy are usually associated to potential overvaluations of small caps stocks leading to price corrections and yielding negative returns. The relationship between the VIX index and CRB Industrial return with the size factors is through market expectations on increased risk premiums and the deterioration of the economic outlook. More specifically, positive variations of the VIX index and negative variations of the CRB Industrial return signal increases in risk aversion levels and a drop in commodity prices, yielding in turn, a higher probability of shorting the size factor.

The rest of the article is structured as follows. Section 2 presents the methodological background needed to construct the optimal dynamic investment strategies. Section 3 discusses the choice of state variables proxying the dynamics of the SMB factor for each economy. The empirical application in Section 4 illustrates the 
differences in performance between the passive SMB strategy and its dynamic counterpart for financial data from European, U.S. and U.K. markets. Section 5 concludes. Tables and figures are collected in an appendix.

\section{Methodological background}

The methodology to derive the dynamic optimal portfolio strategy combines two strands of the literature on optimal portfolio allocation. First, we build on the recent literature by Brandt (1999), Ait-Sahalia and Brandt (2001) and Brandt et al. (2009) and propose portfolios with optimal weights determined by linear functions of some state variables proxying the stage of the cycle, credit conditions and market risk aversion. This approach establishes a link between the distribution of the returns on the investor's portfolio, the macroeconomic environment and investor preferences. Second, we explore the empirical literature assessing the relationship between the economic cycle, market risk aversion and economic sentiment and the relative performance of small and large firms. The existence of empirical correlations between these variables underpins our choice of state variables proxying the set of information available to the investor and relevant for determining their dynamic investment strategies.

\subsection{Small caps and large caps: an asset allocation approach}

This section presents the problem of an investor who needs to allocate her wealth between a risk-free asset with return $r f_{t}$ and a risky portfolio, denominated hereafter as the naïve size factor portfolio, with return $R_{S M B, t+1}$. The optimal portfolio weight $\alpha_{S M B t}$ allocated to the size factor is defined as a linear function of all the state variables that are expected to have predictive power for describing the dynamics of this factor and potentially affect investor's expected marginal utility, see for example Brandt (1999). These variables are related by the following portfolio return specification: 


$$
R_{p, t+1}=\alpha_{r f, t} r f_{t}+\alpha_{S M B, t} R_{S M B, t+1}
$$

with $r f_{t}$ the return on a risk-free asset specific to the economic area under study, $R_{t+1, S M B}$ is the return on the size factor, and $\alpha_{r f, t}$ and $\alpha_{S M B, t}$ the share of investment in each asset and such that $\alpha_{r f, t}+\alpha_{S M B, t}=1$. Hence, we assume that the investor can invest directly in a security that replicates the return on the idiosyncratic SMB strategy. This portfolio can be expressed as:

$$
R_{p, t+1}=r f_{t}+\alpha_{S M B, t} R_{S M B, t+1}^{e}
$$

with $R_{S M B, t+1}^{e}$ the excess return on the size factor. We impose the assumption $-1<\alpha_{S M B, t}<2$ that avoids excessive and unrealistic leverage. Values of $\alpha_{S M B t}$ between -1 and 0 reflect short positions on the size factor and a long position on the risk-free asset; values between 0 and 1 reflect a long position in both assets in the portfolio; a value of $\alpha_{S M B, t}$ between 1 and 2 signals a short position on the risk-free asset compensated by a significant long position on the size factor. The case $\alpha_{S M B t}=1$ corresponds to the passive strategy given by replicating the SMB factor during that period. The optimal portfolio weight $\alpha_{S M B, t}$ is defined as:

$$
\alpha_{S M B, t}=\alpha\left(Z_{t} ; \beta\right)=Z_{t}^{\prime} \beta
$$

with beta a vector of coefficients to be optimally selected. The investor's optimal asset allocation problem is to maximize its expected utility conditional on the sigma-algebra determined by the available information set. Assuming $\beta$ is constant this problem is mathematically stated as the unconditional problem:

$$
\underset{\beta}{\operatorname{Max}} E\left[U\left(R_{p, t+1}\left(\alpha\left(Z_{t} ; \beta\right)\right)\right) \mid \Omega_{t}\right]
$$


with $U\left(\mathrm{R}_{p, t+1} ; \beta\right)$ denoting investor's utility, $\Omega_{t}$ the corresponding sigma-algebra and $E\left[\bullet \Omega_{t}\right]$ the mathematical expectation conditional on $\Omega_{\uparrow}$. Brandt et al. (2009) show that the expected utility of the investor is connected to all the moments of the distribution of the portfolio return, and the optimization implicitly takes into account the relationship between the state variables and expected returns, variances and even higher-order moments to the extent they affect the optimized portfolio returns, and therefore the investor's expected utility.

The first-order conditions of this maximization problem are:

$$
E\left[U^{\prime}\left(R_{p, t+1}\left(\alpha\left(Z_{t} ; \beta\right)\right)\right) R_{S M B, t+1}^{e} \mid \Omega_{t}\right]=0,
$$

with $U^{\prime}\left(R_{p, t+1} ; \beta\right)$ denoting investor's marginal utility. Further, under the assumption that the information contained in $\Omega_{t}$ is completely reflected by the state vector $Z_{t}$, the above condition implies that:

$$
E\left[U^{\prime}\left(R_{p, t+1}\left(\alpha\left(Z_{t} ; \beta\right)\right)\right) R_{S M B, t+1}^{e} \otimes Z_{t}\right]=0
$$

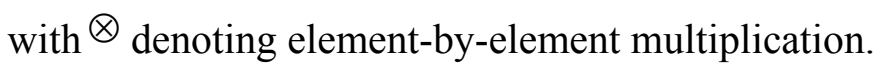

\subsection{Estimation of the model parameters}

The above representation of the optimal asset allocation problem yields a testable representation that can be implemented using generalized method of moments (GMM) techniques. Let $h\left(R_{p, t+1}, Z_{t} ; \beta\right)=U^{\prime}\left(R_{p, t+1} ; \beta\right) R_{S M B, t+1}^{e} \otimes Z_{t}$ be a $\mathrm{k} \times 1$ vector with $\mathrm{k}$ being the length of $Z_{\mathrm{t}}$. The sample analogue of expression (6) is:

$$
(1 / T) \sum_{t=0}^{T-1} h\left(R_{p, t+1}, Z_{i} ; \beta\right)=0 .
$$


Under standard regularity conditions on the utility function the estimation problem of the relevant parameters can be interpreted as a method of moments estimator as developed by Hansen (1982). The idea behind the Generalized Method of Moments (GMM) is to choose $\beta$ so as to make the sample moment $(1 / T) \sum_{t=0}^{T-1} h\left(R_{p, t+1}, Z_{t} ; \beta\right)$ as close to zero as possible. This is achieved by minimizing the scalar:

$$
\left[(1 / T) \sum_{t=0}^{T-1} h\left(R_{p, t+1}, Z_{t} ; \beta\right)\right]^{\prime} V_{T}^{-1}\left[(1 / T) \sum_{t=0}^{T-1} h\left(R_{p, t+1}, Z_{t} ; \beta\right)\right]
$$

where $V_{\mathrm{T}}$ admits different choices of the covariance matrix. In a first stage $V_{\mathrm{T}}$ is the identity matrix and in a second stage, to gain efficiency, this matrix is replaced by a consistent estimator of the asymptotic covariance matrix, $V$, of the random vector $h\left(R_{p, t+1}, Z_{t} ; \bar{\beta}\right)$. To find a suitable expression for this estimator we exploit condition (5) that implies that $h\left(R_{p, t+1}, Z_{t} ; \beta\right)$ is a martingale difference sequence with respect to $\Omega_{t}$. Using this fact, $\mathrm{V}_{\mathrm{T}}$ can be expressed as:

$$
V_{T}=(1 / T) \sum_{t=0}^{T-1} h\left(R_{p, t+1}, Z_{t} ; \bar{\beta}\right) h^{\prime}\left(R_{p, t+1}, Z_{t} ; \bar{\beta}\right)
$$

with $\bar{\beta}$ a consistent estimator of $\beta$ obtained from minimizing (8) in the first stage. Asymptotic inference on these coefficients is obtained using standard results on GMM estimation. Thus, the asymptotic covariance matrix of the GMM estimator vector for $f$ is:

$$
\Gamma_{T}=(1 / T)\left[G_{T} V_{T}^{-1} G_{T}\right]^{-1},
$$

where

$$
G_{T}=(1 / T) \sum_{t=0}^{T-1} \frac{\partial h\left(R_{p, t+1}, Z_{t} ; \bar{\beta}\right)}{\partial \beta}
$$


In order to make these theoretical results operational we assume that the investor's utility function is isoelastic or CRRA and takes the following form:

$$
U\left(R_{,, t+1}\right)=\frac{\left(1+R_{p, t+1}\right)^{1-\gamma}}{1-\gamma}
$$

with $\gamma$ the investor's constant relative risk aversion (CRRA) coefficient. If $\gamma=1$ the utility function is $U\left(R_{p, t+1}\right)=\log \left(1+R_{p, t+1}\right)$. The choice of this family of utility functions is standard in portfolio theory problems and asset pricing, see Brandt (1999) and references therein.

\section{3 Portfolio performance measures}

We use the following metrics to measure the economic performance of the portfolios: 1) the Sharpe ratio, calculated as the mean portfolio excess return divided by the portfolio return volatility, 2) the Sortino ratio, calculated as the average period return in excess of the target return, which is the risk-free rate, divided by the target downside deviation, and 3) the difference in certainty equivalent returns (CERs), defined as the annualized difference between the CER calculated from the utility of the models that incorporate the state variables and the CER corresponding to the utility using the naïve or passive size factor strategy. The CER is in this context a guaranteed return that makes the investor indifferent in expected terms between the risky portfolio $R_{p, t+1}$ and the riskless strategy paying off CER. Under CRRA utility, the CER is computed as:

$$
C E R=\left((1-\gamma) T^{-1} \sum_{t=1}^{T} U\left(1+R_{p, t+1}\right)\right)^{1 /(1-\gamma)}-1 .
$$

\section{Choice of state variables}


In our dynamic setting, in order to be able to determine the timing for reversing the investment positions between the risk-free asset and the SMB factor it is crucial to be able to predict the dynamics of the factor. To do this we need to understand the variables that exhibit predictive power for the dynamics of the returns on the SMB factor.

Theoretically, the presence of credit market imperfections, and more specifically, the existence of lending agency costs have larger negative effects on the economic performance of small firms than of large firms, see the seminal article by Gertler and Gilchrist (1994). This negative effect is reflected by the presence of a higher borrowing premium on external financing by small firms than large firms. During recessions the underlying risk aversion increases and augments the cost of borrowing by the private sector. Whereas large firms can seek for alternative ways of financing during these periods, small firms still need to rely on the standard credit channels and can suffer more from adverse credit conditions. This effect is likely to reduce production and profits for small firms compared to large firms. The stance on monetary policy also has asymmetric effects in terms of firm size. Thus, it is expected that monetary policy tightening affects more adversely small firms than large firms by dampening their access to credit. The relationship between monetary policy tightening and an impoverishment in credit market conditions is also discussed by Bernanke et al. (1999).

Small and large firms also differ on their level of liquidity. This factor gains importance during recession periods characterized by a drain in liquidity that is more relevant for small firms than large firms. During these periods investors require a higher expected return for small firms than for large firms to compensate for potential liquidity shortages under financial distress, see Amihud (2002). Vassalou (2004) also suggests that small cap firms have higher default risk than large firms. This author actually 
argues that the size effect could be driven by the firms with the smallest capitalization within the small caps group.

The above theories on credit market imperfections are empirically captured by the model proposed by Quirós and Timmermann (2000). These authors propose a twostate Markov Regime Switching model for the conditional mean excess return on equity portfolios classified according to the size factor. In this nonlinear model the conditional mean excess return depends on the one month Treasury-bill rate, the default premium, the annual rate of growth of the monetary base and the dividend yield. The transition probability between states is determined by the annual rate of growth of the Composite Index of Leading Indicators. Quirós and Timmermann (2000) find conditional Sharpe ratios that increase during recessions and fall in the ensuing expansion states, allowing them to implement simple profitable investment rules. The empirical work by these authors illustrates the importance of aggregate credit and monetary policy variables for explaining the dynamics of the size sorted firms' Sharpe ratio. The predictive power of the above variables is also supported by Petkova (2006). This author shows that the success of the SMB factor at describing the cross section of stock returns is partly due to the correlation between the factor and the innovations in variables connected to the investment opportunity set. These variables include the Treasury-bill yield, the default spread, the term spread and the dividend yield.

Another important channel for evaluating the dynamics of size sorted firms is through investor sentiment variables. Baker and Wurgler (2006) show that periods of high investor sentiment predict future underperformance of small caps vs. large caps, suggesting that in those periods the small caps, which are more difficult to value and arbitrage than large caps, are likely to be overpriced. Kurov (2010) shows that investor 
sentiment is also affected by the stance on monetary policy, especially during bear markets and recessions.

The above discussion on the choice of relevant variables to predict the SMB factor highlights the role of variables related to interest rates, overall credit conditions, market risk aversion and economic sentiment. Interest rates are represented by the level and slope factors of the yield curves describing the sovereign bond market of each economy. For Europe, this is obtained from German data on sovereign bonds; for the U.K., the yield curve is obtained from gilts; and for the U.S., from the term structure of Treasury bonds. The level and slope factors of each of these government yield curves are expected to convey information about financing conditions in Europe, U.K. and U.S., respectively; on the business cycle outlook and the underlying risk premia in bond markets, which is linked to the external funding premium faced by firms. Extant financial conditions are also captured in our model by the momentum in the level factor. Market risk aversion is captured by financial indexes such as the three month change of the VIX, often referred to as the fear gauge, and the three month change of the CRB Commodity index. Finally, we consider the survey-based German and U.K. Economic Sentiment Indicators (ESI) provided by the European Commission to capture economic agents' beliefs about current and future economic conditions for Europe and the U.K. Such indicators are not available for the U.S. for the period under study. These indicators are made up of five sectorial confidence indicators with different weights: Industrial confidence indicator (40\%), Services confidence indicator (30\%), Consumer confidence indicator $(20 \%)$, Construction confidence indicator $(5 \%)$ and Retail trade confidence indicator (5\%). Confidence indicators are arithmetic means of seasonally adjusted balances of answers to a selection of questions closely related to the reference variable they are supposed to track. Each ESI is calculated as an index with mean value 
of 100 and standard deviation of 10 over a fixed standardised sample period. Gelper and Croux (2010) illustrate the predictive power of the German ESI indicator for the short term Euro area growth. We hypothesize that the U.K. based ESI may also contain economic sentiment information to have power to predict the relative valuation between small and large caps portfolios for the U.K. market.

It follows from these arguments that our proposed specification for $\alpha_{S M B, t}$ is:

$$
\alpha_{\text {SMB }, t}=\alpha\left(Z_{t} ; \beta\right)=\beta_{0}+\beta_{\text {Level }} \text { Level }_{t}+\beta_{\text {Slope }} \text { Slope }_{t}+\beta_{\text {Level Mom }} \text { Level Mom }_{t}+\beta_{\text {CVX }} \text { CVIX }_{t}+\beta_{\text {CRB }} \text { CRB }_{t}+\beta_{\text {ESI }} \text { ESI }_{t},
$$

for the European and U.K. size factors. For the U.S. market, the relevant weight function is modified by removing the ESI state variable from the above specification and the three-month change of the VIX that is only available from 1986.

\section{Empirical results}

This section assesses the economic performance of the SMB factor as a naïve investment portfolio and compares it against the dynamic version that also considers a risk-free asset and the possibility of time-varying weights allocated to each asset return. Section 4.1 describes the data, Section 4.2 analyses the out-of-sample performance of the static SMB portfolio against different dynamic strategies. Section 4.3 proposes a simple robustness exercise to modifications in the state variables defining the linear portfolio policy.

\subsection{Data description}

Our data covers different periods depending on the market under study as our aim is to fully exploit data availability for each case. For this reason, we consider the period March 1993 to September 2013 for the European market. In this case monthly return data are collected from Bloomberg on the Eurostoxx 50 and the Stoxx Europe Small 
200. The Eurostoxx 50, which is a market capitalization-weighted stock index of 50 large European companies operating within the Euro zone nations, is representative of European large caps. Similarly, the Stoxx Europe Small 200 is chosen as representative of small capitalization companies in Europe ${ }^{1}$. This index covers Austria, Belgium, Denmark, Finland, France, Germany, Greece, Iceland, Ireland, Italy, Luxembourg, the Netherlands, Norway, Portugal, Spain, Sweden, Switzerland and the United Kingdom. Monthly data are also collected from Bloomberg on the German three-month Treasury bill, the VIX index and the CRB Industrial commodity index. The U.K. size factor is constructed as the difference between the return on the FTSE Small caps index and the FTSE 100 return. Similarly, the U.S. SMB factor return is defined as the difference between the Russell 2000 return and the return on the S\&P500 index. For these two countries we consider a larger sample of data than in the European case that spans from January 1986 to September 2013 for the U.K., and from January 1982 to September 2013 for the U.S.

As for the European study, we consider the U.K. and U.S. three-month Treasury bill rate as the level factor. The slope factors acting as state variables are defined for each country as the difference between the 10-year Treasury bond rate and the threemonth Treasury bill rate specific to each sovereign bond market. These two state variables are extracted by applying principal component analysis to the term structure of the corresponding monthly zero-coupon yields available for each market. For the European case, see Figure 1 for the loadings on each component over different maturities, the first principal component explains $97.08 \%$ of the total variance, the share of variance explained by the first two factors is $99.85 \%$ and $99.98 \%$ if we include the third factor. Data on the U.S. Baa-Aaa yield spread are obtained from the U.S. Federal

\footnotetext{
${ }^{1}$ It is important to notice that futures contracts on the large caps and small caps indexes considered in this paper are available for trading and allow the straightforward implementation of the investment strategies proposed in this paper.
} 
Reserve. The ESI is provided by the European Commission. Figure 2 plots the dynamics of the state variables for the period under consideration. We demean and standardize all the state variables in the optimization process.

[Insert Figure 1 and 2 about here]

Table 1 shows the cross-correlations between the period $t$ state variables and the naïve investment strategy return on the European SMB factor in excess of the German three-month Treasury bill rate in period $t+1$. Most of the correlations are modest with the exception of the negative correlation between the level factor of interest rates and the size factor and to a lesser degree between the level momentum and the three-month change of the VIX and CRB indexes. Similar results are obtained for the U.K. and U.S. markets and are omitted for the sake of space.

[Insert Table 1 about here]

We verify that the state variables identified above as potential predictors indeed capture time variations in at least the first and second moments of the return distribution of the SMB factor in excess of the three-month Treasury bill. For that purpose, we set up the following moment conditions:

$$
\begin{aligned}
& E_{t}\left[R_{S M B, t+1}\right]=Z_{t}^{\prime} \gamma, \\
& V_{t}\left[R_{S M B, t+1}\right]=Z_{t}^{\prime} \theta,
\end{aligned}
$$

with $E_{t}[$.$] and V_{t}[$.$] defining the conditional mean and variance. We estimate the$ coefficients $\gamma$ and $\theta$ using GMM. Table 2 presents the regression estimates 
corresponding to the European, U.K. and U.S. size factor. Panel A of Table 2 reports the results for the European example. In this case the estimates show that the level factor of interest rates, the three-month change of the VIX Index and the European economic sentiment index are found to be negatively related to the expected return on the SMB factors in excess of the three-month Treasury bill rate. Interestingly, the three-month change of the VIX Index is also correlated to the conditional variance of the SMB factor. More specifically, the state variable predicts a decrease in the next period's variance of the SMB excess return suggesting that an increase in market risk aversion decreases the expected return of small firms compared to large firms but also the uncertainty about these outcomes making more likely for mean-variance investors to invest on large firms that small firms during these periods. As pointed out by a referee, these empirical results are contrary to a rational, risk-based explanation. More specifically, if the level of risk aversion increases and small firms are perceived riskier than large firms, standard asset pricing formulations imply that investors require a higher risk premium on a portfolio of small firm stocks than on a portfolio of large firm stocks. Our empirical result partially contradicting standard theory can be due to a slow response of the SMB strategy to the state of the market. This under-reaction is exploited by the SMB portfolio to achieve higher returns in these scenarios.

Panel A also reveals a positive effect of the German economic sentiment index on the next period's conditional variance of the excess return on the SMB factor. These two results combined suggest that a larger value of the ESI is associated to a lower expected SMB excess return but with a larger variance. These results indicate a deterioration in the attractiveness of the SMB factor as an asset class as the VIX and the economic sentiment index increase. These results also illustrate the power of the threemonth change in the $\mathrm{CRB}$ Index in predicting the conditional variance of the SMB 
excess return. In particular, we note that an increase in the three-month change in the CRB Index is expected to be followed by a decrease in the variance of the SMB excess return. These results are similar for the U.K. and U.S. markets. It is worth highlighting however the negative effect of the U.S. level momentum on the next period U.S. SMB excess return and the lack of power of the British economic indicator in predicting the first conditional moments of the corresponding size factor. Nevertheless, overall, the results reported in Panels A-C of Table 2 provide ample empirical support to the choice of the proposed state variables for describing the linear portfolio policy specified in (14).

[Insert Table 2 about here]

\subsection{Empirical portfolio performance}

In this section we aim to study the out-of-sample empirical performance of the investment portfolios tracking the European, U.K. and U.S. size factor strategies. We discuss first the statistical relevance of the state variables proposed above in the construction of the simple linear portfolio policy introduced in (14).

\subsubsection{State variables and the portfolio policy}

Table 3 and 4 report the weights of the simple linear portfolio policy corresponding to a risk averse investor maximizing its expected utility characterized by a CRRA power function. In particular, Table 3 reports the values of the parameter estimates for different characterizations of risk aversion embedded in the following values of the parameters $\gamma=(2,5,10,40,100)$ for the European size factor. Table 4 focuses on $\gamma=5$ and presents a comparison of the parameter estimates of the size factor weight functions 
corresponding to Europe, U.K. and U.S. The econometric estimation is performed using a two-step estimator and a weighting matrix that accommodates the presence of heteroskedasticity and autocorrelation up to four lags using the Bartlett kernel. This exercise aims to ascertain the robustness of the results across different degrees of investor risk aversion and across financial markets.

[Insert Table 3 and 4 about here]

Table 3 shows that the sign pattern of the parameter estimates is consistent across gamma, with increasing estimates of the beta coefficients associated with decreasing values of gamma, revealing an inverse relationship between the degree of investor risk aversion and its responsiveness to changes in the information set. Table 3 and 4 provide similar evidence across financial markets on the relationship between the size factors and the state variables. More specifically, our results suggest that the optimal portfolio weights allocated to the size factors are negatively related to the level factor of interest rates and the three-month change of the level factor of interest rates. The effect of the state variable describing economic sentiment is also negative, however, its statistical significance varies depending on the market under consideration. Thus, whereas we observe a negative and statistically significant relationship between the ESI and the European size factor, we do not find a statistically significant relationship between the British counterpart of the ESI state variable and the U.K. size factor. The absence of data on a U.S. economic sentiment index over the whole evaluation period does not allow us to assess this effect for the U.S. size factor.

The above results establish, as expected, that an environment of high interest rates and positive momentum of the level factor affect more adversely small caps, 
making the portfolio weight allocated to the size factor decrease. We also interpret the significant and negative relationship between the German ESI and the optimal weight allocated to the SMB factor as evidence of the existence of two different transmission channels between economic sentiment and the relative performance of small firms compared to large firms. One channel is through the larger negative impact of increases in interest rates on investors' views on small firms' returns due to tighter financing conditions, and a second related channel that affects the size factor through the impact that tighter monetary policies have on investors' valuations of small cap stocks usually leading to downward corrections in market prices and lower returns. This result would be in the spirit of Baker and Wurgler (2006).

Tables 3 and 4 also corroborate the findings observed in Table 2 by revealing the negative relationship between the portfolio weight allocated to the size factors and the three-month change of the VIX. We also observe a positive relationship between the portfolio weight allocated to the size factor and the three-month change of the CRB Industrial return for the European size factor. An interpretation of these results is that increasing levels of market risk aversion, reflected in spikes of the VIX index and the plunge of the commodity index, can trigger a flight to quality and liquidity from small caps to large caps, implying negative returns of the SMB factor during these periods and a short position on the SMB factor portfolio.

\subsubsection{Out-of-sample portfolio performance}

This section analyses the out-of-sample performance of the optimized strategies considering different degrees of leverage. Strategy 1 corresponds to the case of no short sales represented by $0<\alpha_{S M B, t}<1$; Strategy 2 corresponds to the case were short sales are allowed given by $-1<\alpha_{\text {SMB }, t}<1$, and Strategy 3 corresponds to the unrestricted case 
$-1<\alpha_{S M B, t}<2$ permitting for more leverage in the optimized portfolio. Each size portfolio is discussed separately.

[Insert Table 5 about here]

For the European size factor strategy, the first portfolio for the out-of-sample analysis is computed with data from March 1993 to December 1999. After this initial period, the model is re-estimated every year using a rolling window of data until the end of the sample. This is done in such a way that the investor uses the information available up to period $t$, reflected in the values of the state variables, to estimate the dynamic weight function defining the optimal portfolio between time $t$ and $t+1$. Panel A of Table 5 shows the remarkable performance of the size factor and the dynamic strategies (1,2 and 3) out- -of-the-sample. Thus, for the overall out-of-sample period the static SMB portfolio provides an excess return of $6.76 \%$, a Sharpe ratio of 0.70 and a Sortino ratio larger than 1 . In all cases, however, the optimized dynamic strategies outperform the passive SMB factor highlighting the superior performance of the dynamic strategy for the European case. Thus, the average optimal weight ranges from 0.48 for Strategy 2 to 1.11 for Strategy 3. The difference in Sharpe ratio across the optimized strategies and the passive SMB factor ranges from 0.14 units for Strategy 2 to 0.27 units for Strategy 3. The Sortino ratio always attains a value larger than 1.42 compared to a value of 1.10 for the passive strategy, and the out-of-sample certainty equivalent of the optimized strategy is at least 50 basis points per year higher than for the naïve SMB factor, reaching a value of 110 basis points when $-1<\alpha_{S M B, t}<2$.

Panel B of Table 5 reports the out-of-sample results corresponding to the U.S. size factor strategy, which considers an information set smaller than for the European 
and U.K. strategies due to the lack of data on the relevant economic sentiment index and VIX for the entire evaluation period. The first portfolio to carry out the rolling exercise spans the period January 1982 to December 1989. In this case the results are similar in spirit to those obtained for the European case. For this market, and also for the U.K. market, the results are not as striking as for the European size factor. Nevertheless, we note positive values of the Sharpe and Sortino ratios and the certainty equivalent return in all cases. The differences in these performance measures across strategies also highlight the outperformance of the dynamic strategies compared to the passive size portfolio given in this case by the differences in returns between the Russell 2000 index and the S\&P500. It is also worth discussing the staggering kurtosis statistic reported by the strategy allowing for short sales and labelled as Strategy 2. This value suggests large oscillations in the return on that portfolio although with a significant positive mean return.

Panel $\mathrm{C}$ of Table 5 discusses the investment performance corresponding to the U.K. study. The first portfolio needed to carry out the rolling exercise spans the period January 1986 to December 1999. The results are similar to those reported for the previous two markets. The Sharpe and Sortino ratios are superior that for the U.S. strategies and confirm the outperformance of the optimized strategies over the naïve size portfolio. The certainty equivalent return also provides very satisfactory figures. It is interesting that for the U.K. market, it is Strategy 1 the one that reports a very high kurtosis and a lower mean compared to the other two dynamic strategies. This finding together with the rest of performance measures establishes the superior performance of the strategies making allowance for short selling.

These results are confirmed by the evolution of the cumulative excess returns over time for each of the investment strategies and country-specific size factors. The 
dynamics of these excess returns are reported in Figures 3 to 5. As can be readily seen from the plots, the returns on our optimal portfolios dominate those of the naïve strategies in almost the entire out-of-sample period. More specifically, Figure 3 shows that investing 1 Euro in the SMB factor portfolio would yield 1.47 Euros at the end of the period, whereas the dynamic strategies would produce 2.55 Euros, when no short sales are allowed, 2.69 Euros when $-1<\alpha_{S M B, t}<1$ and 5.97 Euros when $-1<\alpha_{S M B, t}<2$. Similarly, Figure 4 shows that investing 1 U.S. dollar in the dynamic strategy not allowing for short sales would yield 1.65 dollars at the end of the period, 2.11 U.S. dollars when $-1<\alpha_{S M B, t}<1$ and 2.85 dollars when $-1<\alpha_{S M B, t}<2$. Note however that in this case the naïve SMB portfolio corresponding to the U.S. market would not yield such a significant cumulative excess return at the end of the period. Figure 5 illustrates the profitability of the different strategies for the U.K. size factor. The results are very similar to those corresponding to the U.S. case and highlight the good performance of the optimized dynamic strategies over the entire out-of-sample period. For the U.K. case, the evolution of the cumulative excess returns reveals some underperformance of the different strategies during the 2007-2008 crisis episodes.

[Insert Figures 3 to 5 about here]

The section concludes with a discussion of the dynamics of the optimal strategies over the out-of-sample period. To preserve space, we only consider Strategy 2 that allows for short selling. Figure 6 plots the dynamics of this optimized strategy over the period January 2000 to September 2013 for the European size factor. The chart suggests the optimality of holding a short position on the SMB factor during the initial period up to May 2001 corresponding to the so-called dot-com bubble, and later, during 
the 2007-2009 episode of financial crisis worldwide. The optimal dynamic strategy is completed by considering a long position on the size factor in the remaining periods. These findings can be rationalized by noting that each of the two periods with a short position on the size factor correspond to a crisis episode in financial markets. As discussed above, the occurrence of crises has asymmetric effects in small caps and large caps firms entailing a negative performance of the naïve size portfolio. Further, the volatility in the dynamics of the optimal weight over these periods could indicate the existence of persistence in the state variables that produces some inertia in the optimal weight function, reflected in a delay on the weight function to adjust to economic conditions and changes in the relative performance between short and large caps stocks.

Similar findings are observed in Figure 7 for the dynamics of the weight function corresponding to the U.S. optimized portfolio. Interestingly, Strategy 2 for the U.K. optimized portfolio reported in Figure 8 exhibits higher volatility of the optimal weight associated to the size factor. This weight function seems to overreact to changes in the information set particularly over crisis episodes.

[Insert Figures 6 to 8 about here]

\subsection{Robustness}

Our final exercise consists on assessing the robustness of the results to including new state variables in the investor information set that could potentially predict the dynamics of the size factor and its impact on the investor marginal utility through its relationship with the overall financing conditions and economic outlook. In particular, we add separately the U.S. Baa-Aaa yield spread, the one-month change in the U.S. Baa-Aaa yield spread and the one-month change in the slope factor of interest rates as state 
variables that could determine the optimal function $\alpha_{S M B, t}$. By doing so, we want to check the stability of the parameter signs and their magnitude, and the possibility of improving investment performance.

We consider first the U.S. Baa-Aaa spread in the investor information set. This spread mirrors credit conditions and is defined as the difference between the yields on Baa and Aaa rated corporate bond portfolios. The choice of this variable as opposed to its European counterparty is due to its availability. This variable is countercyclical as noted by Fama ad French (1989) and expected to proxy the increase in default risk during recessions. Its relation to the size factor is through the differences in rating scores between small and large firms that is reflected in larger differences in borrowing costs. We also consider the one month change in the U.S. Baa-Aaa yield spread and a variable reflecting the term or slope momentum, the one-month change in the slope factor of interest rates. The choice of these variables is justified by Hann and Lee (2006) that find that changes in the default spread and the term spread capture systematic differences in average returns along the size and book-to-market dimensions, making the SMB and HML factors superfluous in explaining the cross-section of portfolios returns sorted on firm size and book-to-market. Intuitively, the increase of the default spread signals an expected deterioration of credit market conditions with stronger negative effects on the small caps that are more vulnerable to changing credit market conditions, see Quiros and Timmermann (2000). Increases of the term spread usually anticipate higher future interest rates controlling for the presence of a bond risk premium that reach their highest values at the trough of the business cycle. The combination of both effects could affect more negatively the performance of small caps compared to large caps in the short run. 
The results in Table 6 show that including the U.S. Baa-Aaa spread from the set of state variables hardly affects the parameter estimates of the rest of state variables in the GMM exercise and the comparison in terms of economic significance between portfolio performances. More importantly, the U.S. Baa-Aaa yield spread is not statistically significant; the information carried by this variable seems to be subsumed under the other state variables. We reach the same conclusions using the U.S. Baa-Aaa yield spread momentum and the slope momentum, which has a negative marginal effect on the optimal weight allocated to the European size factor (p-value equals to 0.11 ). In the light of these results, we maintain the preference for our initial specification of the investor information set. Similar results are obtained for the U.S. and U.K. size factors and omitted for the sake of space.

[Insert Table 6 about here]

\section{Conclusion}

In this paper we discuss the choice of a size factor as a suitable investment style and address the macroeconomic and financial determinants with power to explain its dynamics. These variables and the inclusion of a risk-free asset in the investment opportunity set allow us to derive an optimal investment portfolio given by a long position on the size factor in periods of economic expansion and a short position in periods of economic downturn and financial turbulence that is compensated by a long position in the risk-free asset.

Our empirical analysis also uncovers the existence of a negative relationship between the returns on the size factor, the level factor of interest rates, market risk aversion and variables describing economic sentiment and proxied by the Economic 
Sentiment Index for Germany and the U.K. reported by the European Commission. The rationale behind these relationships is the asymmetric effect of financial turmoil and tight monetary policies in small and large capitalization firms reflected in increases in interest rates, price corrections of overvalued small firms and tighter borrowing and financing conditions.

Our results are meaningful from the perspective of investor's welfare and out-ofsample portfolio performance. Thus, we observe that an investor who follows optimized dynamic size factor strategies attains a higher Sharpe ratio, Sortino ratio and certainty equivalent than under the passive strategy. 


\section{References}

Ait-Sahalia, Y.,\& Brandt, M. (2001). Variable selection for portfolio choice. Journal of Finance, 56, 1297-1351.

Amihud, Y. (2002). Illiquidity and stock returns: cross-section and time-series effects. Journal of Financial Markets, 5, 31-56.

Baker, M., and Jeffrey W., (2006). Investor Sentiment and the Cross Section of Stock Returns, Journal of Finance, 61 (4), 1645-1680.

Bernanke, B., Gertler, M., Gilchrist, S. (1999). The financial accelerator in a quantitative business cycle framework. Handbook of Macroeconomics, ( J. B.Taylor and M).

Brandt, M. (1999). Estimating portfolio and consumption choice: A conditional method of moments approach. Journal of Finance, 54, 1609-46.

Brandt, M., Santa Clara, P., \& Valkanov, R. (2009). Parametric portfolio policies exploiting the characteristics in the cross section of equity returns. Review of Financial Studies, 22, 3411-3447.

Fama, E., \& French, K. (1993). Common risk factors in the returns on stock and bonds. Journal of Financial Economics, 33, 3-56.

Fama, E. and K. French, (1996). Multifactor explanations of asset pricing anomalies, Journal of Finance, 51, 55-84.

Gelper, S., Croux, C. (2010). On the construction of the European Economic Sentiment Index. Oxford Bulletin of Economics and Statistics, 72, 47-62.

Gertler, M., Gilchrist, S. (1994). Monetary policy, business cycles and the behaviour of small manufacturing firms. Quarterly Journal of Economics, 109, 309-340.

Hann, J., Lee, H. (2006). Yield spreads as alternative risk factors for size and book-tomarket. Journal of Financial and Quantitative Analysis, 41 (2), 245-269. 
Hansen, L. (1982). Large sample properties of generalized method of moments estimators. Econometrica, 50, 1029-1054.

Kapadia, H. (2011). Tracking down distress risk. Journal of Financial Economics, 102, 167-182.

Kurov, A. (2010). Investor sentiment and the stock market's reaction to monetary policy. Journal of Banking and Finance, 34, 139-149.

Kyotaki, N., Moore, J. (1997). Credit cycles. Journal of Political Economy, 105, 211-248.

Quirós, G., Timmermann, A. (2000). Firm size and cyclical variation in stock returns. Journal of Finance, 55, 1229-1262.

Liew, J., Vassalou, M. (2000). Can book-to-market, size and momentum be risk factors that predict economic growth? Journal of Financial Economics, 57, 221-245.

Petkova, R. (2006). Do the Fama-French factors proxy for innovation in predictive variables?. Journal of Finance, LXI (2), 581-612.

Vassalou, M., Xing, Y. (2004). Default risk in equity returns. The Journal of Finance, LIX (2), 831-868. 
Table 1: Correlation matrix

\begin{tabular}{|l|c|c|c|c|c|c|c|}
\hline & $R_{S M B, t+1}^{e}$ & Level $_{\mathrm{t}}$ & Slope $_{\mathrm{t}}$ & Level Momentum $_{\mathrm{t}}$ & CVIX $_{\mathrm{t}}$ & CRB $_{\mathrm{t}}$ & ESI $_{\mathrm{t}}$ \\
\hline$R_{S M B, t+1}^{e}$ & 1 & & & & & & \\
\hline Level $_{\mathrm{t}}$ & -0.33 & 1 & & & & & \\
\hline Slope $_{\mathrm{t}}$ & 0.03 & 0.03 & 1 & & & & \\
\hline Level Momentum $_{\mathrm{t}}$ & -0.03 & 0.14 & -0.09 & & & & \\
\hline CVIX $_{\mathrm{t}}$ & -0.18 & 0.07 & -0.07 & -0.26 & & & \\
\hline CRB $_{\mathrm{t}}$ & 0.14 & 0.04 & 0.04 & 0.48 & -0.35 & 1 & \\
\hline ESI $_{\mathrm{t}}$ & -0.18 & 0.01 & -0.24 & 0.17 & 0.06 & 0.04 & 1 \\
\hline
\end{tabular}

This table presents the correlation matrix of the investment strategy return, that consists of going long in the European small caps and short in the European large caps (SMB), in excess of the German three-month Treasury bill rate at period $t+1$, and the state variables at period $t$ : the level factor of European interest rates (Level), the slope factor of European interest rates (Slope), the three-month change of the level factor of European interest rates (Level Momentum), the three-month change of VIX index (CVIX), the three-month CRB Industrial return (CRB), and the Germany economic sentiment indicator (ESI). The return horizon is one month. The sample period covers the period from March 1993 to September 2013. 
Table 2: SMB factor return predictability

Panel A: Europe (1993/2013)

\begin{tabular}{|c|c|c|c|c|c|c|}
\hline$E_{t}\left[R_{t+1, S M B}^{e}\right]=Z_{t}^{\prime} \gamma$ & Level $_{t}$ & Slope $_{t}$ & $\begin{array}{c}\text { Level } \\
\text { Momentum }_{\mathrm{t}}\end{array}$ & CVIX $_{t}$ & $\mathrm{CRB}_{\mathrm{t}}$ & $\mathrm{ESI}_{\mathrm{t}}$ \\
\hline$\gamma$ & -1.76 & 0.27 & -0.97 & -0.52 & -0.14 & -0.43 \\
\hline t-stat & $(-6.46)$ & (1.44) & $(-1.30)$ & $(-2.52)$ & $(-0.71)$ & $(-2.09)$ \\
\hline $\operatorname{VaR}_{t}\left[R_{t+1, S M B}^{e}\right]=Z_{t}^{\prime} \theta$ & Level $_{\mathrm{t}}$ & Slope $_{t}$ & $\begin{array}{c}\text { Level } \\
\text { Momentum }_{t}\end{array}$ & CVIX $_{t}$ & $\mathrm{CRB}_{\mathrm{t}}$ & $\mathrm{ESI}_{\mathrm{t}}$ \\
\hline 6 & -0.26 & 0.07 & -4.23 & -3.93 & -2.71 & 1.48 \\
\hline t-stat & $(-0.28)$ & $(0.08)$ & $(-0.90)$ & $(-1.90)$ & $(-2.10)$ & $(2.05)$ \\
\hline
\end{tabular}

This table presents predictive regressions for the expected return and the variance of the investment strategy return, that consists of going long in the European small caps and short in the European large caps (SMB), in excess of the German three-month Treasury bill rate at period $t+1$, and the state variables at period $t$ : the level factor of European interest rates (Level), the slope factor of European interest rates (Slope), the three-month change of the level factor of European interest rates (Level Momentum), the three-month change of VIX index (CVIX), the three-month CRB Industrial return (CRB), and the German economic sentiment indicator (ESI). The return horizon is one month. We use data from Bloomberg from March 1993 to September 2013. 
Panel B: U.S. (1982/2013)

\begin{tabular}{|c|c|c|c|c|}
\hline$E_{t}\left[R_{t+1, S M B}^{e}\right]=Z_{t}^{\prime} \gamma$ & Level $_{\mathrm{t}}$ & Slope $_{\mathrm{t}}$ & Level Momentum $_{\mathrm{t}}$ & CRB $_{\mathrm{t}}$ \\
\hline$\gamma$ & -0.26 & 0.21 & -0.50 & 0.10 \\
\hline $\mathrm{t}$-stat & $(-1.23)$ & $(0.21)$ & $(-1.99)$ & $(0.50)$ \\
\hline $\operatorname{VaR}_{t}\left[R_{t+1, S M B}^{e}\right]=Z_{t}^{\prime} \theta$ & Level $_{\mathrm{t}}$ & Slope $_{\mathrm{t}}$ & Level Momentum & CRB $_{\mathrm{t}}$ \\
\hline $\boldsymbol{t}$ & 0.44 & 0.05 & 1.29 & -1.52 \\
\hline $\mathrm{t}$-stat & $(0.40)$ & $(0.04)$ & $(1.07)$ & $(-1.86)$ \\
\hline
\end{tabular}

This table presents predictive regressions for the expected return and the variance of the investment strategy return, that consists of going long in the U.S. small caps and short in the U.S. large caps (SMB), in excess of the U.S. threemonth Treasury bill rate at period $t+1$, and the state variables at period $t$ : the level factor of U.S. interest rates (Level), the slope factor of U.S. interest rates (Slope), the three-month change of the level factor of U.S. interest rates (Level Momentum) and the three-month CRB Industrial return (CRB). The return horizon is one month. We use data from Bloomberg from January 1982 to September 2013. 
Panel C: U.K. (1986/2013)

\begin{tabular}{|c|c|c|c|c|c|c|}
\hline$E_{t}\left[R_{t+1, S M B}^{e}\right]=Z_{t}^{\prime} \gamma$ & Level $_{\mathrm{t}}$ & Slope $_{\mathrm{t}}$ & $\begin{array}{c}\text { Level } \\
\text { Momentum }_{\mathrm{t}}\end{array}$ & $\mathrm{CVIX}_{\mathrm{t}}$ & CRB $_{\mathrm{t}}$ & ESI $_{\mathrm{t}}$ \\
\hline$\gamma$ & -2.07 & -0.41 & -0.16 & -0.81 & 0.56 & -0.31 \\
\hline $\mathrm{t}$-stat & $(-4.55)$ & $(-0.90)$ & $(-0.57)$ & $(-3.84)$ & $(1.48)$ & $(-0.97)$ \\
\hline $\operatorname{VaR}_{t}\left[R_{t+1, S M B}^{e}\right]=Z_{t}^{\prime} \theta$ & Level $_{\mathrm{t}}$ & Slope $_{\mathrm{t}}$ & $\begin{array}{c}\text { Level } \\
\text { Momentum }_{\mathrm{t}}\end{array}$ & $\mathrm{CVIX}_{\mathrm{t}}$ & CRB $_{\mathrm{t}}$ & ESI $_{\mathrm{t}}$ \\
\hline 6 & -3.26 & -2.47 & -1.80 & -3.65 & -0.04 & -1.31 \\
\hline $\mathrm{t}-$ stat & $(-1.25)$ & $(-1.32)$ & $(-1.22)$ & $(-2.06)$ & $(-0.02)$ & $(-0.81)$ \\
\hline
\end{tabular}

This table presents predictive regressions for the expected return and the variance of the investment strategy return, that consists of going long in the U.K. small caps and short in the U.K. large caps (SMB), in excess of the U.K. threemonth Treasury bill rate at period $t+1$, and the state variables at period $t$ : the level factor of U.K. interest rates (Level), the slope factor of U.K. interest rates (Slope), the three-month change of the level factor of U.K. interest rates (Level Momentum), the three-month change of VIX index (CVIX), the three-month CRB Industrial return (CRB), and the U.K. economic sentiment indicator (ESI). The return horizon is one month. We use data from Bloomberg from January 1986 to September 2013. 
Table 3: Simple linear portfolio policy. In-sample results

\begin{tabular}{|c|c|c|c|c|c|}
\hline Variable & $\mathrm{CRRA}=2$ & $\mathrm{CRRA}=5$ & $\mathrm{CRRA}=10$ & $\mathrm{CRRA}=40$ & $\mathrm{CRRA}=100$ \\
\hline$\beta_{\text {Level }}$ & -7.13 & -3.46 & -1.79 & -0.44 & -0.16 \\
\hline t-stat & $(-4.90)$ & $(-4.91)$ & $(-4.98)$ & $(-4.94)$ & $(-4.64)$ \\
\hline$\beta_{\text {Slope }}$ & 1.58 & 0.44 & 0.18 & 0.05 & 0.03 \\
\hline t-stat & $(1.02)$ & $(0.52)$ & $(0.41)$ & $(0.49)$ & $(0.84)$ \\
\hline$\beta_{\text {Level Momentum }}$ & -11.25 & -7.13 & -3.80 & -1.00 & -0.43 \\
\hline t-stat & $(-1.96)$ & $(-2.13)$ & $(-2.17)$ & $(-2.31)$ & $(-2.60)$ \\
\hline$\beta_{C V I X}$ & -3.69 & -1.80 & -0.93 & -0.24 & -0.10 \\
\hline t-stat & $(-2.91)$ & $(-3.13)$ & $(-3.19)$ & $(-3.23)$ & $(-3.17)$ \\
\hline$\beta_{C R B}$ & 2.77 & 1.50 & 0.79 & 0.20 & 0.10 \\
\hline t-stat & $(2.45)$ & $(2.78)$ & $(2.85)$ & (2.99) & (3.13) \\
\hline$\beta_{E S I}$ & -2.84 & -1.25 & -0.64 & -0.16 & -0.06 \\
\hline t-stat & $(-2.92)$ & $(-2.87)$ & $(-2.89)$ & $(-2.90)$ & $(-2.64)$ \\
\hline
\end{tabular}

This table shows estimates of the optimal investment strategy policy, which consists of going long in the European small caps and short in the European large caps (SMB), specified in equation (14) and optimized for a power utility function with different CRRA coefficients $(\gamma=2,5,10,40,100)$ using these state variables: the level factor of European interest rates (Level), the slope factor of European interest rates (Slope), the three-month change of the level factor of European interest rates (Level Momentum), the three-month change of VIX index (CVIX), the three-month CRB Industrial return (CRB), and the German economic sentiment indicator (ESI). The in-sample period covers the period from March 1993 to September 2013. 
Table 4: Simple linear portfolio policy for CRRA=5. Europe, US and U.K. in-sample results.

\begin{tabular}{|c|c|c|c|}
\hline Variable & Europe & US & U.K. \\
\hline$\beta_{\text {Level }}$ & -3.46 & -1.08 & -1.51 \\
\hline t-stat & $(-4.91)$ & $(-2.03)$ & $(-1.96)$ \\
\hline$\beta_{\text {Slope }}$ & 0.44 & 0.15 & -0.20 \\
\hline t-stat & $(0.52)$ & $(0.3)$ & $(-0.24)$ \\
\hline$\beta_{\text {Level Momentum }}$ & -7.13 & -1.33 & -1.78 \\
\hline t-stat & $(-2.13)$ & $(-2.14)$ & $(-3.02)$ \\
\hline$\beta_{C R B}$ & 1.50 & 0.47 & 0.12 \\
\hline t-stat & $(2.78)$ & $(1.45)$ & $(0.24)$ \\
\hline$\beta_{C V I X}$ & -1.80 & & -1.70 \\
\hline t-stat & $(-3.13)$ & & $(-3.45)$ \\
\hline$\beta_{E S I}$ & -1.25 & & 0.50 \\
\hline t-stat & $(-2.87)$ & & $(1.34)$ \\
\hline
\end{tabular}

This table shows estimates of the optimal investment strategy policy, which consists of going long in the European, U.S. or U.K. small caps and short in the European, U.S. or U.K. large caps (SMB), specified in equation (14) and optimized for a power utility function with CRRA coefficient $\gamma=5$ using these state variables: the European, U.S. or U.K. three-month Treasury bill rate (Level), the European, U.S. or U.K. 10 Year Treasury rate less the three-month Treasury bill rate (Slope), the three-month change of the level factor (Level Momentum), the three-month change of VIX index (CVIX), the three-month CRB Industrial return (CRB), and the German or U.K. economic sentiment indicator (ESI). The sample period covers the period March 1993, January 1982 or January 1986 to September 2013 in the European, U.S and U.K. markets respectively. 
Table 5: Investment performance of the optimized out-of-sample strategies

\begin{tabular}{|c|c|c|c|c|c|c|c|c|}
\hline Strategy & Mean & Skewness & Kurtosis & SR & $\begin{array}{l}\text { Sortino } \\
\text { ratio }\end{array}$ & CER & $\begin{array}{c}\text { Mean } \\
\alpha\end{array}$ & $\begin{array}{c}\text { STD } \\
\alpha\end{array}$ \\
\hline SMB & 6.76 & 0.03 & 0.27 & 0.70 & 1.10 & & & \\
\hline \multicolumn{9}{|l|}{ ESI (all in) $0<\alpha_{S M B, t}<1$} \\
\hline Level, Slope, Level Momentum, CVIX, CRB, & 7.63 & -0.01 & 0.52 & 0.84 & 1.42 & 0.50 & 0.48 & 0.82 \\
\hline \multicolumn{9}{|l|}{ ESI (all in) $-1<\alpha_{S M B, t}<1$} \\
\hline ESI (all in) $-1<\alpha_{S M B, t}<2$ & & & & & & & & \\
\hline
\end{tabular}

Panel B: US (Jan 1990/Sept 2013)

\begin{tabular}{|c|c|c|c|c|c|c|c|c|}
\hline Level, Slope, Level Momentum, , CRB (all in) & 2.66 & -0.05 & 2.78 & 0.35 & 0.65 & 3.49 & 0.46 & 0.62 \\
\hline \multicolumn{9}{|l|}{$0<\alpha_{S M B, t}<1$} \\
\hline Level, Slope, Level Momentum, CRB (all in) & 5.50 & 0.81 & 3.79 & 0.38 & 0.55 & 0.05 & 0.59 & 1.17 \\
\hline
\end{tabular}

Panel C: U.K. (Jan 2000/Sept 2013)

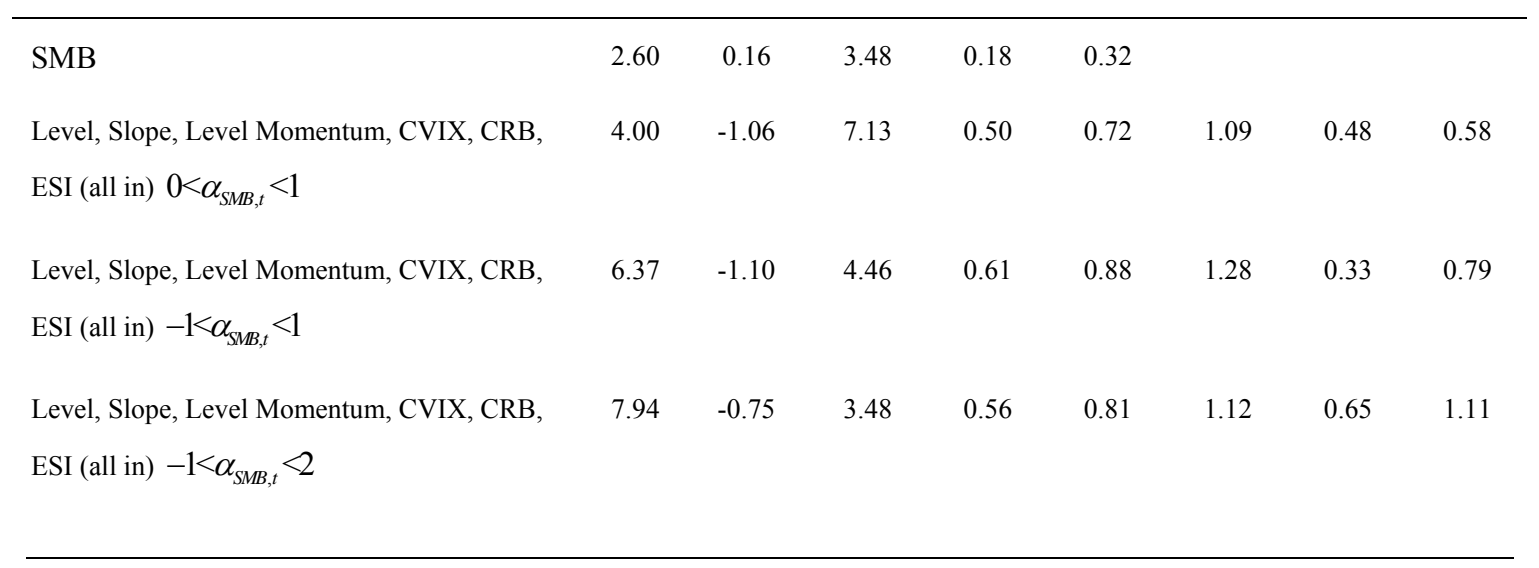

Out-of-sample performance of the optimized investment strategies considering different degrees of leverage: 1) $\left.0<\alpha_{S M B, t}<12\right)-1<\alpha_{S M B, t}<1$ and 3) $-1<\alpha_{S M B, t}<2 . \mathrm{CRRA}=5$. Data span March 1993 to December 1999 for the European case, from January 1982 to December 1989 for the US case and from January 1986 to December 1999 for the U.K. market to estimate the first optimal parametric portfolio. After this, the model is re-estimated every year using expanding rolling window of data until the end of the sample. The investor uses the estimates in period t to form the optimal European size portfolio between $t$ and $t+1$. The naïve investment strategy return displays statistics for the strategy of going long in the small caps and short in the large caps (SMB). SR is the optimized portfolio's Sharpe ratio; CER measures the difference in the annualized certainty equivalent of each strategy vs. the naïve currency carry trade. The mean $\alpha$ is the average optimal currency carry trade bet and STD $\alpha$ is its standard deviation. 
Table 6: Simple linear portfolio policy. In-sample robust analysis. European size factor

\begin{tabular}{|c|c|c|c|c|}
\hline Variable & $\mathrm{CRRA}=5$ & $\mathrm{CRRA}=5$ & $\mathrm{CRRA}=5$ & SMB \\
\hline$\beta_{\text {Level }}$ & -3.03 & -3.46 & -3.88 & \\
\hline t-stat & $(-2.92)$ & $(-4.93)$ & $(-5.27)$ & \\
\hline$\beta_{\text {Slope }}$ & 0.41 & 0.42 & 0.05 & \\
\hline t-stat & $(0.49)$ & $(0.50)$ & $(0.07)$ & \\
\hline$\beta_{\text {Level Momentum }}$ & -7.33 & -6.95 & -7.27 & \\
\hline t-stat & $(-2.11)$ & $(-2.09)$ & $(-2.23)$ & \\
\hline$\beta_{\text {CVIX }}$ & -1.78 & -1.76 & -1.73 & \\
\hline t-stat & $(-3.11)$ & $(-3.12)$ & $(-2.92)$ & \\
\hline$\beta_{C R B}$ & 1.71 & 1.72 & 1.66 & \\
\hline t-stat & $(2.44)$ & $(2.13)$ & (3.11) & \\
\hline$\beta_{E S I}$ & -0.95 & -1.20 & -1.43 & \\
\hline t-stat & $(-1.89)$ & $(-2.85)$ & $(-3.02)$ & \\
\hline$\beta_{\text {Spread Baa/Aaa }}$ & 0.54 & & & \\
\hline t-stat & $(0.67)$ & & & \\
\hline$\beta_{\text {Spread Baa/Aaa Momentum }}$ & & 0.46 & & \\
\hline t-stat & & $(0.42)$ & & \\
\hline$\beta_{\text {Slope Momentum }}$ & & & -3.96 & \\
\hline t-stat & & & $(-1.56)$ & \\
\hline Mean excess return & 16.48 & 16.06 & 16.31 & -8.87 \\
\hline SR & 1.36 & 1.35 & 1.38 & -0.82 \\
\hline Sortino Ratio & 2.97 & 2.89 & 2.98 & -0.98 \\
\hline CER & 30.62 & 29.92 & 30.90 & \\
\hline
\end{tabular}

This table shows estimates of the optimal investment strategy policy, which consist of going long in the European small caps and short in the European large caps (SMB), specified in equation (14) and optimized for a power utility function with a CRRA coefficient $(\gamma=5)$ using different specifications that include the U.S. Baa-Aaa yield spread, the U.S. Baa-Aaa yield spread momentum and the slope factor momentum respectively. The table also reports the mean excess returns, Sharpe ratio, Sortino ratio and the CER defined as the difference in the annualized certainty equivalent of the optimized strategy vs. the naïve investment strategy return $(\mathrm{SMB})$. 


\section{FIGURES}

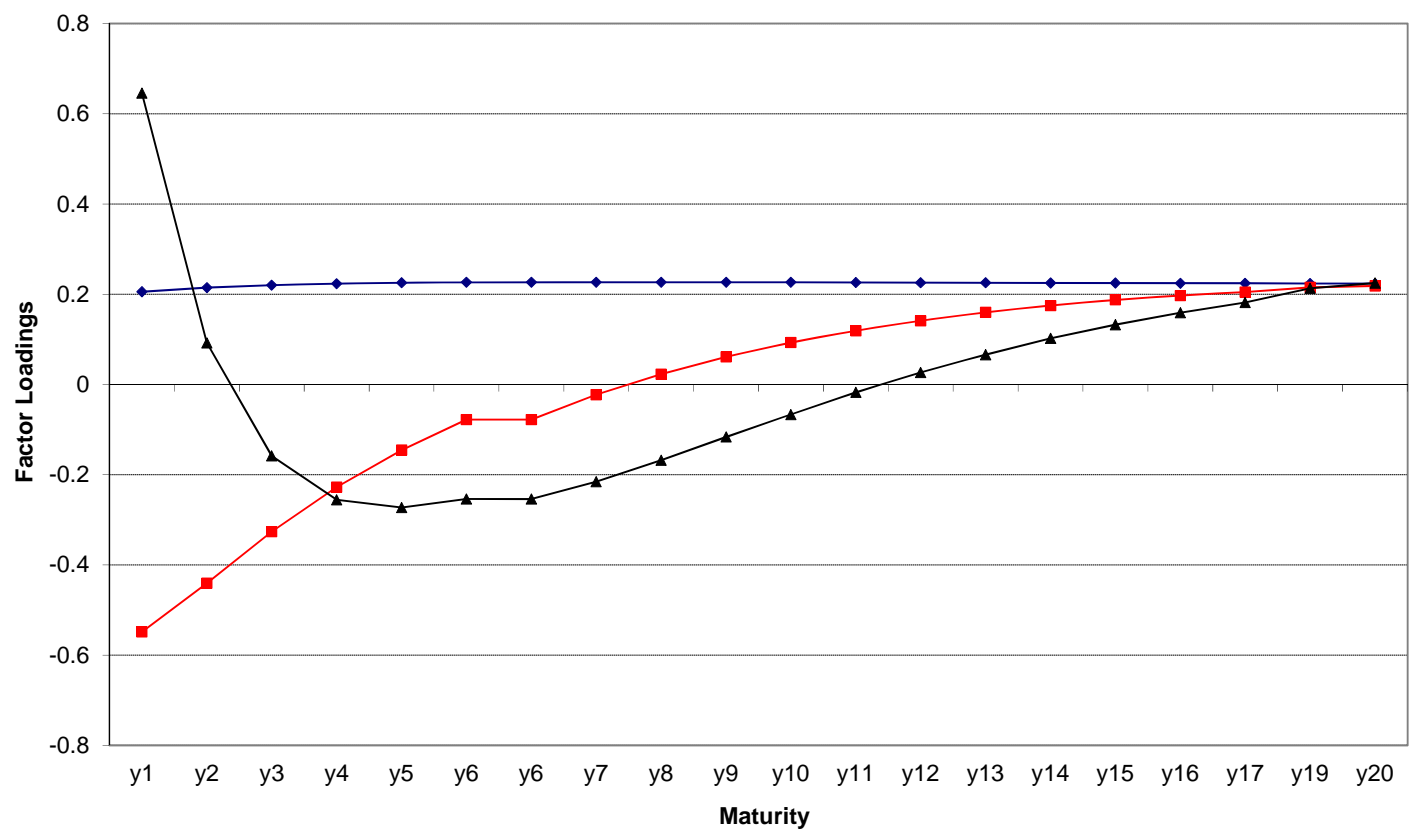

Figure.1: Three most important factor loadings driving the German zero-coupon yield curve.

This figure plots the three most important factor loadings driving the German zero-coupon yield curve. These factor loadings are obtained from the Principal Component analysis of monthly observations of the database of German zero-coupon yields available at Deutsche Bundesbank for the period March 1993 to September 2013. 

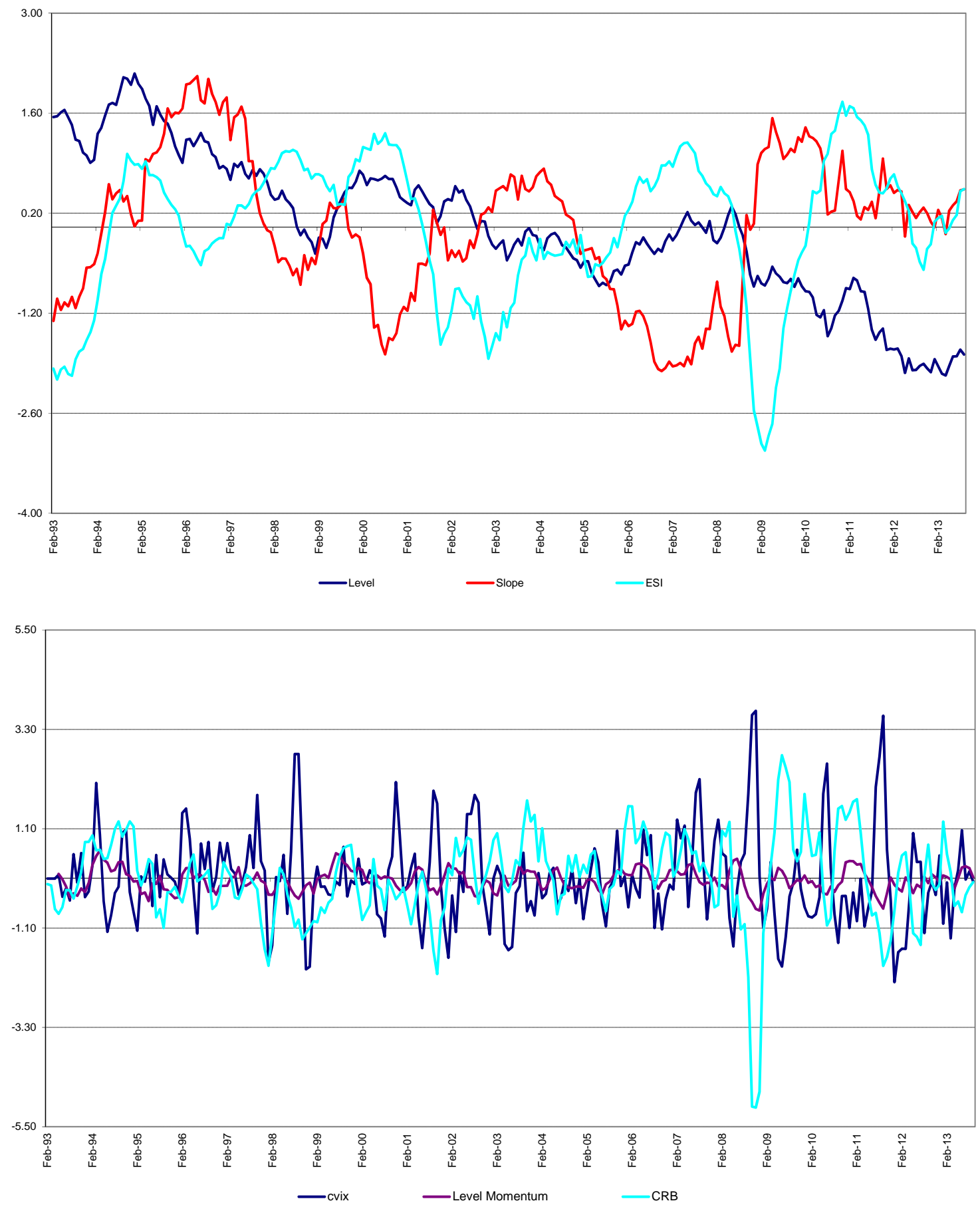

Fig.2: State variables dynamics

This figure plots the standardized across time state variables time series dynamics in the period from January 1993 to September 2013 . the level factor of European interest rates (Level), the slope factor of European interest rates (Slope), the three-month change of the level factor of European interest rates (Level Momentum), the three-month change of VIX index (CVIX), the three-month CRB Industrial return (CRB), and the Germany economic sentiment indicator (ESI). 


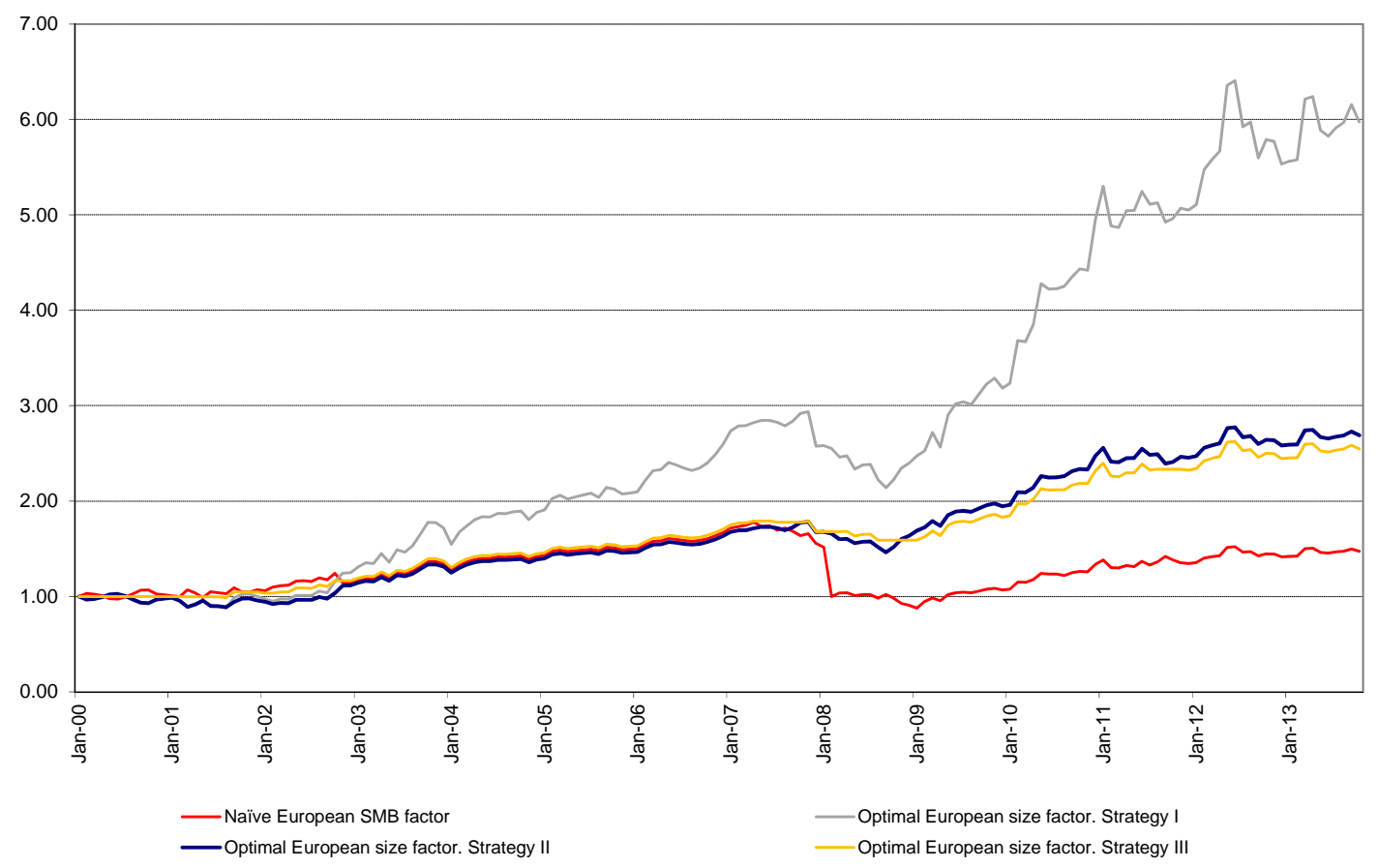

\section{Fig.3: Evolution of out-of-sample cumulative excess returns}

This figure plots the out-of-sample optimal European size factor and naïve European size factor cumulative excess returns. The optimal European size factor excess returns are computed for a linear portfolio specification (see eqn (14)). We use data from March 1993 to December 1999 to estimate the first optimal parametric portfolio. After this, the model is re-estimated every year using a rolling window of data until the end of the sample. The investor uses the estimates in period $\mathrm{t}$ to form the optimal European size portfolio between $\mathrm{t}$ and $\mathrm{t}+1$, given the observed realization at time $\mathrm{t}$ of the state variables. We analyse the out-of-the-sample performance of the optimized strategies considering different degrees of leverage: 1) no short sales are allowed, $0<\alpha_{S M B, t}<1$ (Strategy I), 2) short sales are allowed $-1<\alpha_{S M B, t}<1$ (Strategy II) and $-1<\alpha_{S M B, t}<2$ (Strategy III). The naïve investment strategy return (SMB) displays statistics for the strategy of going long in the European small caps and short in the European large caps. 


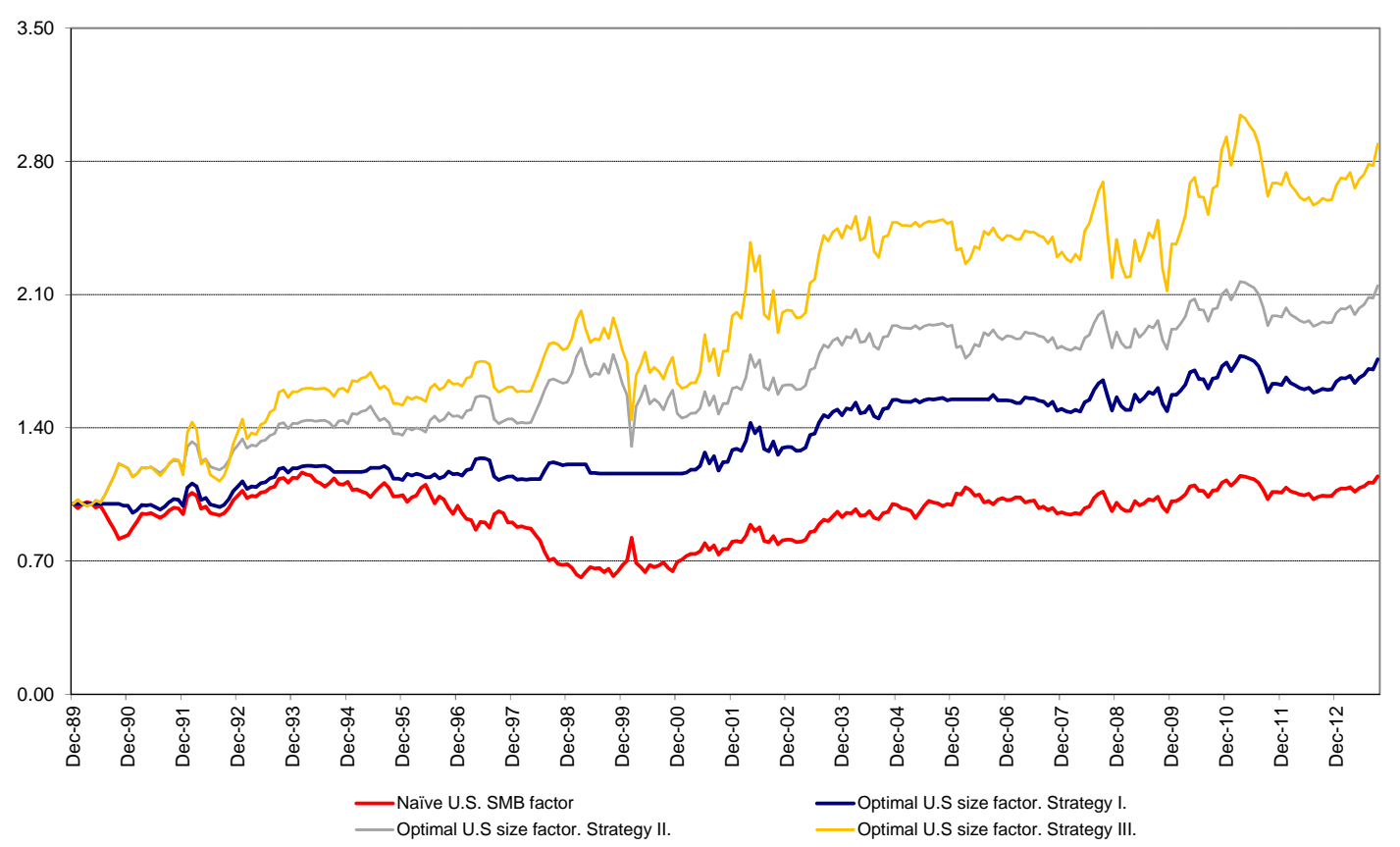

\section{Fig.4: Evolution of out-of-sample cumulative excess returns}

This figure plots the out-of-sample optimal U.S. size factor and naïve U.S. size factor cumulative excess returns. The optimal U.S. size factor excess returns are computed for a linear portfolio specification (see eqn (14)). We use data from January 1982 to December 1989 to estimate the first optimal parametric portfolio. After this, the model is re-estimated every year using a rolling window of data until the end of the sample. The investor uses the estimates in period $t$ to form the optimal European size portfolio between $t$ and $t+1$, given the observed realization at time $t$ of the state variables. We analyse the out-of-the-sample performance of the optimized strategies considering different degrees of leverage: 1) no short sales are allowed, $0<\alpha_{S M B, t}<1$ (Strategy I), 2) short sales are allowed $-1<\alpha_{S M B, t}<1$ (Strategy II) and $-1<\alpha_{S M B, t}<2$ (Strategy III). The naïve investment strategy return (SMB) displays statistics for the strategy of going long in the U.S. small caps and short in the U.S. large caps. 


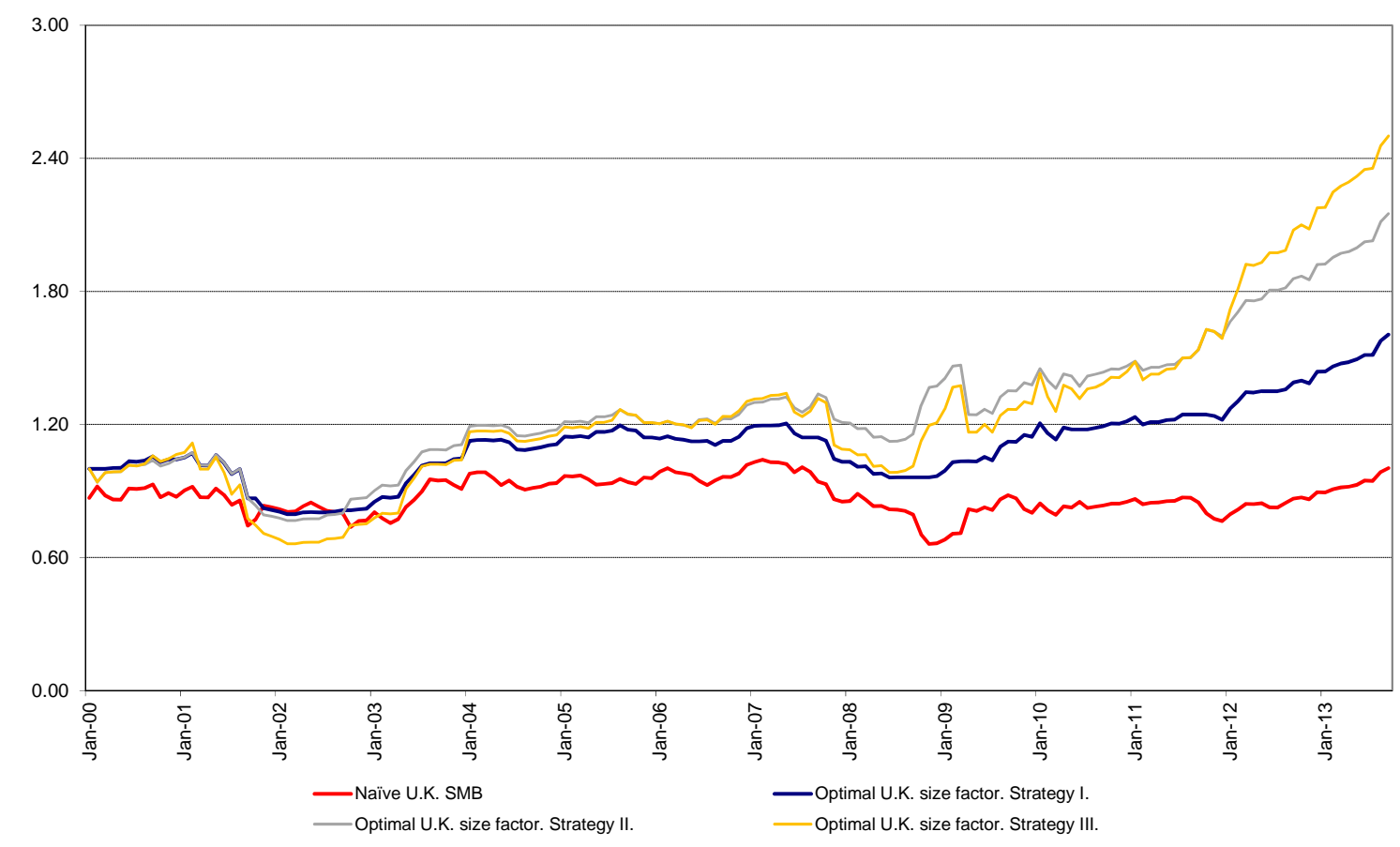

\section{Fig.5: Evolution of out-of-sample cumulative excess returns}

This figure plots the out-of-sample optimal U.K. size factor and naïve U.K. size factor cumulative excess returns. The optimal U.K. size factor excess returns are computed for a linear portfolio specification (see eqn (14)). We use data from January 1986 to December 1999 to estimate the first optimal parametric portfolio. After this, the model is re-estimated every year using a rolling window of data until the end of the sample. The investor uses the estimates in period $t$ to form the optimal European size portfolio between $t$ and $t+1$, given the observed realization at time $t$ of the state variables. We analyse the out-of-the-sample performance of the optimized strategies considering different degrees of leverage: 1) no short sales are allowed,

$0<\alpha_{S M B, t}<1$ (Strategy I), 2) short sales are allowed $-1<\alpha_{S M B, t}<1$ (Strategy II) and $-1<\alpha_{S M B, t}<2$ (Strategy III). The naïve investment strategy return (SMB) displays statistics for the strategy of going long in the U.K. small caps and short in the U.K. large caps. 


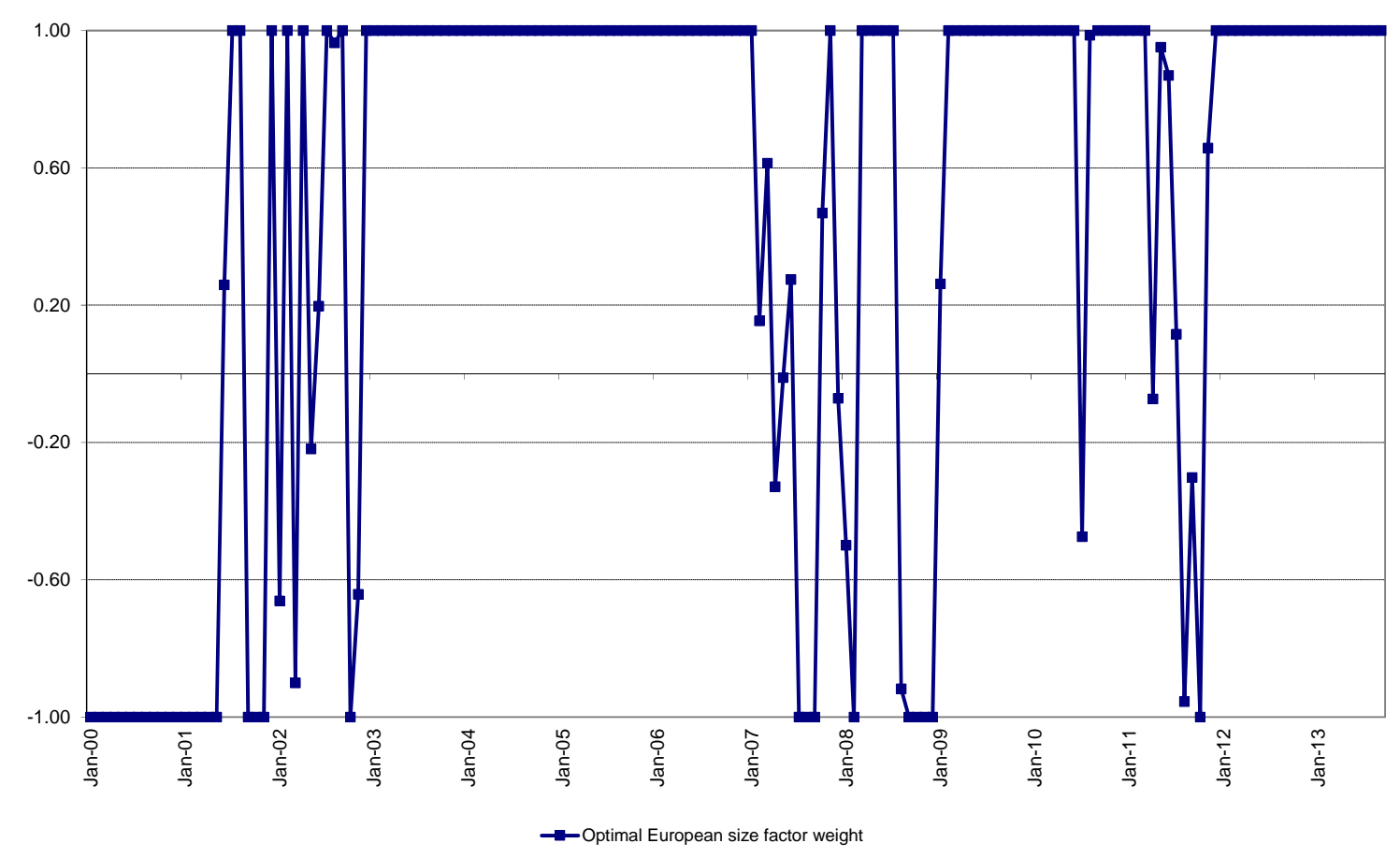

Fig. 6: Out-of-sample optimal European size factor

This figure shows the out-of-sample optimal European size factor portfolio policy for a power utility function with a relative risk aversion parameter equal to 5 and a linear portfolio specification (14) from January 2000 to September 2013, assuming $-1<\alpha_{S M B, t}<1$. 


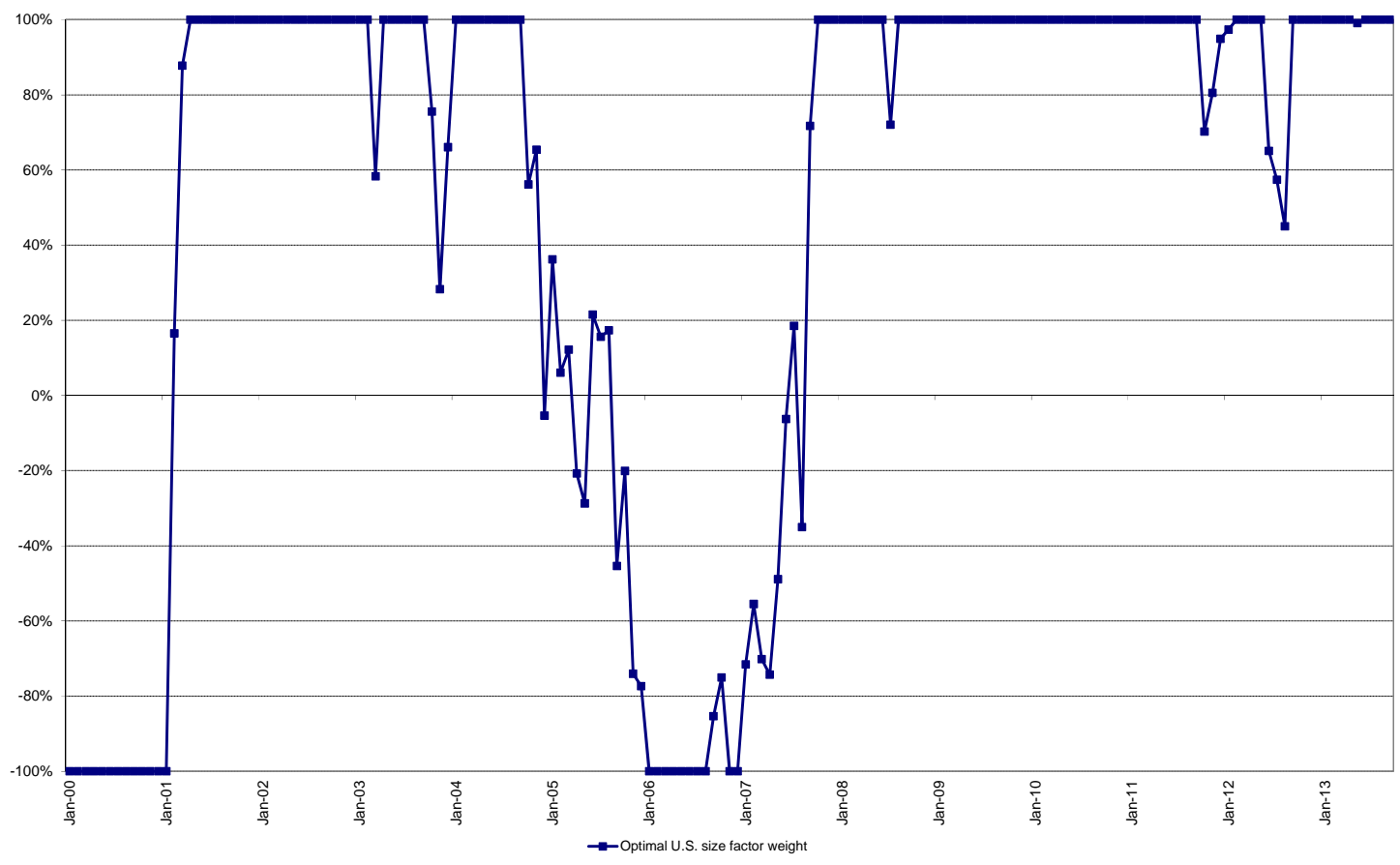

Fig. 7: Out-of-sample optimal U.S. size factor

This figure shows the out-of-sample optimal U.S: size factor portfolio policy for a power utility function with a relative risk aversion parameter equal to 5 and a linear portfolio specification (14) from January 2000 to September 2013, assuming $-1<\alpha_{S M B, t}<1$. 


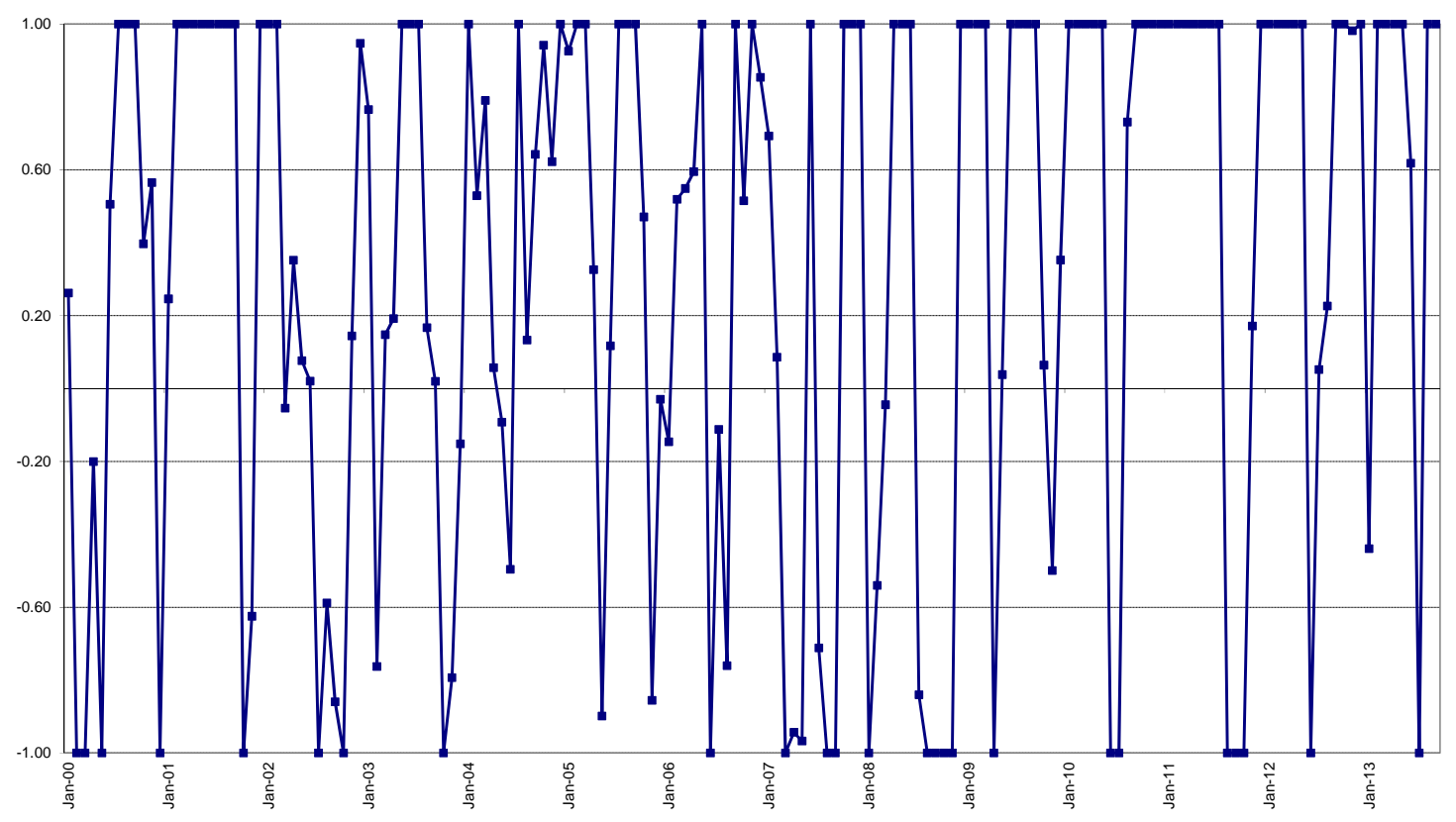

$\rightarrow$ Optimal U.K. size factor weight

Fig. 8: Out-of-sample optimal U.K. size factor

This figure shows the out-of-sample optimal U.K. size factor portfolio policy for a power utility function with a relative risk aversion parameter equal to 5 and a linear portfolio specification (14) from January 2000 to September 2013, assuming $-1<\alpha_{S M B, t}<1$. 